\title{
The effect of applying a head-weight device on cervical angle and pain of neck muscles
}

\author{
Jin-Hong Kim ${ }^{\mathrm{a}}$, Jong-Gun Kim ${ }^{\mathrm{b}}$, Kwang-Sun Do ${ }^{\mathrm{c}}$, Jongeun Yim ${ }^{\mathrm{d}}$ \\ ${ }^{a}$ Department of Rehabilitation, Gachon University Gil Medical Center, Incheon, Republic of Korea \\ ${ }^{b}$ Department of Rehabilitation, Deundeunhan Hospital, Ilsan, Republic of Korea \\ 'Department of Rehabilitation, International St. Mary's Hospital, Incheon, Republic of Korea \\ ${ }^{d}$ Department of Physical Therapy, College of Health and Welfare, Sahmyook University, Seoul, Republic of Korea
}

Objective: The purpose of this study was to measure the change in pain threshold of levator scapular muscle, carniovertebral angle, and head position angle when applying a head-weight device on healthy adult.

Design: Cross-sectional study.

Methods: This study was conducted with 21 healthy adult male and female who voluntarily agreed to participate in this study after being informed of the purpose and method of this study. After measuring the cervical angle and pain threshold of levator scapular muscle, subject was instructed to walk for 5 minutes on a treadmill at a speed of less than $5 \mathrm{~km} / \mathrm{h}$ while wearing after wearing head-weight device of $0.5 \mathrm{~kg}$. Then, cervical spine angle and pain threshold of levator scapula muscle were re-measured. Measurement of cervical spine angle was conducted with photo by using the Bluebeam Revu software and the pain pressure thresholds (PPTs) were measured using an electronic algometer over potential trigger points on the body.

Results: The results cervical angle showed a significant change, from $49.62^{\circ}$ to $52.10^{\circ}(p<0.05)$. PPT showed a significant change, from 30.71 to $36.89(p<0.05)$.

Conclusions: These findings suggest that applying head-weight device has a positive influence on increasing cervical angle and reducing pain when applied as a therapeutic intervention method of forward head posture.

Key Words: Cervical angle, Forward head posture, Head-weight device

\section{Introduction}

With the change into the era of information, there has been a dramatic increase, worldwide, in the use of video display terminals such as mobile phones, tablets, personal computers, etc. [1]. Particularly, there has been an increase in users of smart phones where a considerable amount of information can be obtained. According to National Information Agency survey research in 2013 in Korea, the number of smart phone users was reported to be 24 million and smart phone use hours were reported to be 4.1 hours on average [2].

In general, users maintain the posture of bending the neck and looking downward in order to view the smart phone device. There is a physical change followed by repetitive and continuous use of such video display terminals and one of the representative postures is an inappropriate forward head posture, one of cranio-cervical postures [3]. The definition of this posture is a posture where the external auditory canal, which is the center line of the head, is shifted to the front of the location of the acromion of the shoulder [4]. According to the research by Szeto et al. [5], long-term maintenance of postures where the head is shifted forward decreases lordosis of the lower cervical spine and can be a cause of musculoskeletal problems such as 'upper crossed syndrome' where there is increased kyphosis of the upper

Received: 1 March, 2016 Revised: 2 June, 2016 Accepted: 7 June, 2016

Corresponding author: Jongeun Yim

Department of Physical Therapy, College of Health and Welfare, Sahmyook University, 815 Hwarang-ro, Nowon-gu, Seoul 01795, Republic of Korea Tel: 82-2-3399-1637 Fax: 82-2-3399-1639 E-mail: obok05@gilhospital.com

(c) This is an Open-Access article distributed under the terms of the Creative Commons Attribution Non-Commercial License (http://creativecommons.org/licens es/by-nc/4.0) which permits unrestricted non-commercial use, distribution, and reproduction in any medium, provided the original work is properly cited.

Copyright $@ 2016$ Korean Academy of Physical Therapy Rehabilitation Science 
thoracic vertebrae. Moreover, with the increase in load of the cervical spine followed by shifting of the head toward the front of gravity at the center line of the head, it not only causes structural change but also causes abnormal muscle contraction in the cranio-cervical muscles that support the weight of the head [6]. According to a recent study, it was reported that there is a dramatic increase in load received by the cervical spine with the increase in the forward bend angle of the head. The weight of an adult's head in neutral position is $10-12$ pounds. There is an increase in load toward the neck with the tilt of the head toward the front and the weight is calculated to be $27,40,49$, and 60 pounds at $15^{\circ}, 30^{\circ}, 45^{\circ}$, and $60^{\circ}$ respectively [7]. Such increase in biodynamical stress followed by forward head posture becomes a cause of musculo- skeletal problems such as neck pain, headache, and temporomandibular dysfunction [8-11].

Unconscious neurological postural control of the neck and head is controlled by elements such as the vestibular apparatus, proprioceptive sense of the cervical spine, and the ocular righting mechanism $[12,13]$. Various methods have been tried to adjust such imbalanced posture based on the above mentioned neuro-physiological posture adjustment elements and head-weight device created by Pettibon; among them is a new tool that has been used to correct postural defect through neuro-muscular re-education $[14,15]$. There have been several studies conducted to examine the influence of head weight on forward head posture. Changes were measured with X-ray photo by applying a head-weight device to patients with forward head posture for 8 weeks and were reported that there was a decrease in forward head posture and increase in cervical lordosis after the intervention $[16,17]$. However, the limitation of these previous studies lies in that the intervention was conducted in combination of a head-weight device and spinal manipulation instead of a head-weight device alone and the research design was a case report and pilot study. Therefore, the purpose of this study was to measure the changes in pain threshold of levator scapular muscle, carniovertebral angle, and head position

Table 1. General characteristics of participant

$(\mathrm{N}=21)$

\begin{tabular}{lc}
\hline \multicolumn{1}{c}{ Characteristic } & Value \\
\hline Sex $($ male/female $)$ & $16 / 5$ \\
Age $(\mathrm{y})$ & $30.81(3.92)$ \\
Height $(\mathrm{cm})$ & $171.29(8.34)$ \\
Weight $(\mathrm{kg})$ & $69.57(15.18)$ \\
\hline
\end{tabular}

Values are presented as mean (SD). angle when applying a head-weight device in healthy adults.

\section{Methods}

\section{Subjects}

This study was conducted with 21 healthy adult male and female who voluntarily agreed to participate in this study after listening to explanations on the purpose and method of this study. In regards to the selection criteria of subjects, persons without neck and shoulder problems, experience of wounds, pain, sensor abnormality, and others in neck and shoulders for the past 6 months, or congenital malformation, or surgical and neurological disorders were included. The average age of subjects was 30.81 years, average height was $171.29 \mathrm{~cm}$, and average weight was $69.57 \mathrm{~kg}$ (Table 1).

All protocols and procedures were approved by the Institutional Review Board of Sahmyook University (Seoul, Korea), and all the subjects signed a statement of informed consent before the study began.

\section{Procedure}

In order to measure the cervical spine angle before the experiment, a photo was taken with a fixed camera from the side after attaching a marker to $\mathrm{C} 7$ and the subject seated on the flat chair. Measurement of the cervical spine angle was conducted with the photo by using the Bluebeam Revu software (Pasadena, CA, USA). After measuring the pain threshold of the levator scapular muscle, subjects were instructed to walk on the treadmill for 5 minutes on the treadmill under the speed of $5 \mathrm{~km} / \mathrm{h}$ while wearing a head weight of $0.5 \mathrm{~kg}$ (Figure 1) [18]. Then, cervical spine angle and pain threshold of the levator scapular muscle were re-measured.

\section{Outcome measures}

\section{Cervical angle measurement}

The subject's feet were in contact with the ground with 90 degrees of hip and knee flexion. If necessary, a footrest was used to maintain the angle of the hips and knees. The monitor was placed in line at midline and at eye level of the subject. The camera was set at a height of $0.93 \mathrm{~m}$ using a tripod that was $1.5 \mathrm{~m}$ from the subject. The craniovertebral angle was identified at the intersection of a horizontal line passing through the $\mathrm{C} 7$ spinous process and a line joining the midpoint of the tragus of the ear to the skin overlying the $\mathrm{C} 7$ spinous process. Head position angle evaluates the head status in relation to the trunk and indicates the vertical distance between the chin and sternum. It is the angle between the 


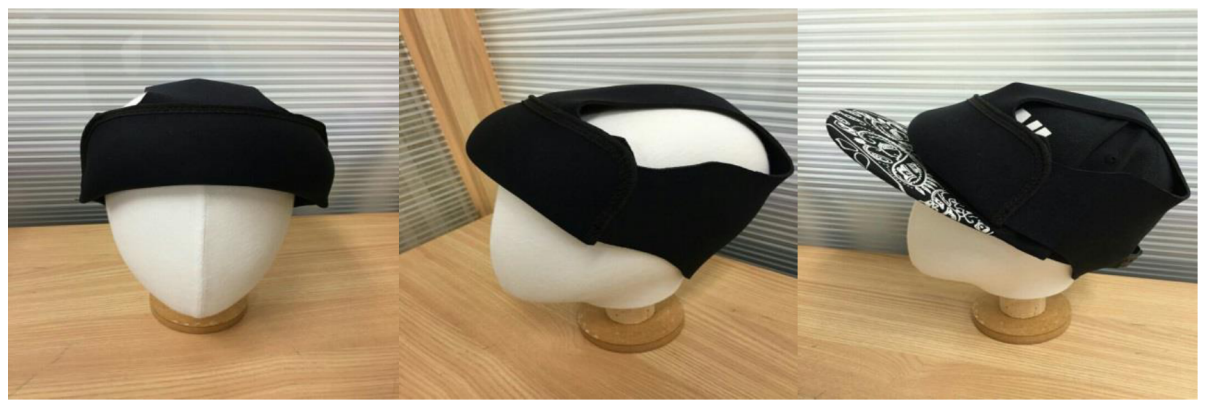

Figure 1. Head-weight device.

tragusmanubrium line and the line extending from the center point of the chin to the tragus. Similar to the craniovertebral angle, there is no standard cut-off point for this value, but a larger head position angle may be associated with a longer forward head posture [19,20].

\section{Pain pressure threshold}

The pain pressure thresholds (PPTs) were measured using an electronic algometer (Jtech Medical, Midvale, UT, USA) over potential trigger points on the body. The examiner identified a trigger point by palpating and exerting vertical pressure on the skin. The examiner increased the pressure at a rate of $1 \mathrm{~kg} / \mathrm{s}$ until the subject experienced pain or an unpleasant feeling, then the PPT values were measured 3 times on levator scapular muscle. The inter-rater reliability of the digital pressure gauge on pain threshold is higher by 0.75 [21,22].

\section{Statistical analysis}

SPSS ver. 15.0 for Windows (SPSS Inc., Chicago, IL, USA) was applied for statistical analysis of the results. Descriptive statistics was used for general history of subjects. A paired t-test was performed for comparison of the cervical angle and PPTs. The alpha level was set at 0.05 for all analyses.

\section{Results}

This study was conducted on 21 participants, whose general characteristics are listed in Table 1 . There was a significant increase in cervical angle, from $49.62^{\circ}$ to $52.10^{\circ}(p<$ $0.05)$. PPT showed a significant change, from 30.71 to 36.89 $(p<0.05)$ (Table 2).

\section{Discussion}

Long-term use of video display terminals, such as smart
Table 2. Comparison of cervical angles and pain pressure threshold $(\mathrm{N}=21)$

\begin{tabular}{lccc}
\hline \multicolumn{1}{c}{ Parameter } & Pre-test & Post-test & $p$ \\
\hline Cervical angle $\left(^{\circ}\right)$ & $49.62(6.34)$ & $52.10(6.23)$ & 0.006 \\
Pain pressure threshold & $30.71(7.89)$ & $36.89(9.86)$ & 0.007 \\
$\left(\mathrm{~kg} / \mathrm{cm}^{2}\right)$ & & & \\
\hline
\end{tabular}

Values are presented as mean (SD).

phones, can lead to inappropriate postures such as a forward head posture and slouched posture [5]. In regards to forward head posture, the head is shifted in front of the anatomical gravity midline and the head is rotated toward the back in an attempt to have straight sight under such posture. Then, there is an increase in extension of the lower cervical spine and a loss of cervical lordosis upon continuous load exertion. Also, it may lead to chronic pain in neck and shoulder muscles as it causes continuous and abnormal muscle tension $[16,23]$. Previous studies have determined various treatment methods for forward head posture such as stretching, joint mobilization, electronic stimulation treatment, heart muscle strengthening, and other treatment options $[17,24,25]$. Although aforementioned intervention methods for treatment are effective, it requires a considerable amount of time and cost. Accordingly, the purpose of this study was to examine the application of a head weight on cervical angle and pain threshold of the levator scapulae muscle with a single group based on the assumption that there will be a change in forward head posture together with a change in cervical pain on the foundation of preceding studies on the head-weight device intervention method which had an influence on forward head posture treatment without considerable amount of time and study [26].

As a result of conducting the experiment with two groups, one with application of general physical treatment and forward head posture corrective treatment, and the other group with only general physical treatment for 6 months with 96 
cervical neuromuscular end patients as its subject, Diab and Moustafa [27] reported that there was an increase in the angle of the cervical spine and decrease in pain for the group with application of both general physical treatment and forward head posture treatment. Also, according to a study by Yoo [25] which examined the angle of the cervical spine and activation of the upper trapezius muscle before and after applying Kinesio tape (ATEX; Ildong, Seoul, Korea) to the cervical spine area while using a computer (with 12 adults who use the computer for a long period of time as its subjects), it was revealed to have positive influence on both cervical angle and muscle activation. According to findings of recent research, most smart phone users go into forward head posture in order to view a small screen which produces an increase in bending angle of the head, thus causing cervical joint and ligament damage due to load exerted by the gravity and head weight [7]. Also, as a result of assessing the relationship between smart phone use and musculoskeletal disease of the upper limb, Berolo et al. [28] reported neck pain (68\%), back pain (62\%), and shoulder pain (49\%). The study by Chang et al. [29] also presented a similar result.

As a result of conducting the cervical angle examination, there was an increase from $49.62^{\circ}\left(6.34^{\circ}\right)$ to $52.10^{\circ}\left(6.23^{\circ}\right)$ before and after wearing head the weight device and it was found to be statistically significant. Such results imply that the application of the head-weight device has brought about positive influence to change in forward head posture followed by influence on cervical extension. Also, as a result of conducting an experiment on pain threshold of levator scapulae muscle, there was an increase from 30.71 (7.89) to 36.89 (9.86) before and after wearing the head-weight device and it was found to be statistically significant. Such results imply that the application of the head-weight device has brought about positive influence in reducing the pain of the levator scapulae muscle followed by a change in cervical angle.

Integrating the above mentioned research results, use of head-weight device has a positive influence on increasing cervical angle and reducing pain when it was applied as a therapeutic intervention method of forward head posture. However, there is a limitation in generalizing the findings of this study due to the fact that there was small number of subjects, duration of experiment time was short, and only healthy adult male and female without pathological problems were selected as the subjects. Therefore, long-term study shall be conducted with subjects who actually suffer from a forward head posture and more detailed effect mech- anism shall be examined with examination on changes in muscle activation when applying a head-weight device.

\section{Conflict of Interest}

The authors declared no potential conflicts of interest with respect to the authorship and/or publication of this article.

\section{References}

1. Wu H, Wang Y, Dong N, Yang F, Lin Z, Shang X, et al. Meibomian gland dysfunction determines the severity of the dry eye conditions in visual display terminal workers. PloS one 2014;9:e105575.

2. Kee IK, Byun JS, Jung JK, Choi JK. The presence of altered craniocervical posture and mobility in smartphone-addicted teenagers with temporomandibular disorders. J Phys Ther Sci 2016; 28:339-46.

3. Kendall HO, Kendall FP. Developing and maintaining good posture. Phys Ther 1968;48:319-36.

4. Kendall FP. Fifteenth Mary McMillan lecture: this I believe. Phys Ther 1980;60:1437-43.

5. Szeto GP, Straker L, Raine S. A field comparison of neck and shoulder postures in symptomatic and asymptomatic office workers. Appl Ergon 2002;33:75-84.

6. Harrison DE, Harrison DD, Betz JJ, Janik TJ, Holland B, Colloca $\mathrm{CJ}$, et al. Increasing the cervical lordosis with chiropractic biophysics seated combined extension-compression and transverse load cervical traction with cervical manipulation: nonrandomized clinical control trial. J Manipulative Physiol Ther 2003; 26:139-51.

7. Hansraj KK. Assessment of stresses in the cervical spine caused by posture and position of the head. Surg Technol Int 2014;25: 277-9.

8. Fernández-de-las-Peñas C, Alonso-Blanco C, Cuadrado ML, Pareja JA. Forward head posture and neck mobility in chronic tension-type headache: a blinded, controlled study. Cephalalgia 2006;26:314-9.

9. Garrett TR, Youdas JW, Madson TJ. Reliability of measuring forward head posture in a clinical setting. J Orthop Sports Phys Ther 1993; 17:155-60.

10. Hanten WP, Lucio RM, Russell JL, Brunt D. Assessment of total head excursion and resting head posture. Arch Phys Med Rehabil 1991;72:877-80.

11. Lau HM, Chiu TT, Lam TH. Measurement of craniovertebral angle with electronic head posture instrument: criterion validity. $\mathrm{J}$ Rehabil Res Dev 2010;47:911-8.

12. Vestibulospinal control of posture and locomotion. Prog Brain Res 1988;76:1-442.

13. Seaman DR, Winterstein JF. Dysafferentation: a novel term to describe the neuropathophysiological effects of joint complex dysfunction. A look at likely mechanisms of symptom generation. J Manipulative Physiol Ther 1998;21:267-80.

14. Morningstar M. Cervical curve restoration and forward head 
posture reduction for the treatment of mechanical thoracic pain using the pettibon corrective and rehabilitative procedures. $\mathrm{J}$ Chiropr Med 2002;1:113-5.

15. Morningstar MW. Cervical hyperlordosis, forward head posture, and lumbar kyphosis correction: a novel treatment for mid-thoracic pain. J Chiropr Med 2003;2:111-5.

16. Burgess-Limerick R, Plooy A, Ankrum DR. The effect of imposed and self-selected computer monitor height on posture and gaze angle. Clin Biomech (Bristol, Avon) 1998;13:584-92.

17. Sarig-Bahat H. Evidence for exercise therapy in mechanical neck disorders. Man Ther 2003;8:10-20.

18. Jowett RL, Fidler MW, Troup JD. Histochemical changes in the multifidus in mechanical derangements of the spine. Orthop Clin North Am 1975;6:145-61.

19. Falla D, O'Leary S, Fagan A, Jull G. Recruitment of the deep cervical flexor muscles during a postural-correction exercise performed in sitting. Man Ther 2007;12:139-43.

20. Nemmers TM, Miller JW, Hartman MD. Variability of the forward head posture in healthy community-dwelling older women. J Geriatr Phys Ther 2009;32:10-4.

21. De Rui M, Marini I, Bartolucci ML, Inelmen EM, Bortolotti F, Manzato E, et al. Pressure pain threshold of the cervico-facial muscles in healthy elderly people: the role of gender, age and dominance. Gerodontology 2015;32:274-80.

22. Antonaci F, Sand T, Lucas GA. Pressure algometry in healthy subjects: inter-examiner variability. Scand J Rehabil Med
1998;30:3-8.

23. Sahrmann SA. Does postural assessment contribute to patient care? J Orthop Sports Phys Ther 2002;32:376-9.

24. Gupta BD, Aggarwal S, Gupta B, Gupta M, Gupta N. Effect of deep cervical flexor training vs. conventional isometric training on forward head posture, pain, neck disability index in dentists suffering from chronic neck pain. J Clin Diagn Res 2013;7: 2261-4.

25. Yoo WG. Effect of the Neck Retraction Taping (NRT) on forward head posture and the upper trapezius muscle during computer work. J Phys Ther Sci 2013;25:581-2.

26. Morningstar MW, Strauchman MN, Weeks DA. Spinal manipulation and anterior headweighting for the correction of forward head posture and cervical hypolordosis: a pilot study. J Chiropr Med 2003;2:51-4.

27. Diab AA, Moustafa IM. The efficacy of forward head correction on nerve root function and pain in cervical spondylotic radiculopathy: a randomized trial. Clin Rehabil 2012;26:351-61.

28. Berolo S, Wells RP, Amick BC 3rd. Musculoskeletal symptoms among mobile hand-held device users and their relationship to device use: a preliminary study in a Canadian university population. Appl Ergon 2011;42:371-8.

29. Chang CH, Amick BC 3rd, Menendez CC, Katz JN, Johnson $\mathrm{PW}$, Robertson M, et al. Daily computer usage correlated with undergraduate students' musculoskeletal symptoms. Am J Ind Med 2007;50:481-8. 